\title{
JORGE AMADO EM 1941-1942: LAMPEJO BIOGRÁFICO
}

\section{JORGE AMADO IN 1941-1942: BIOGRAPHICAL GLIMPSE}

Marina Siqueira Drey*

RESUMO: Nos primeiros anos de 1940 Jorge Amado publicou a biografia Vida de Luiz Carlos Prestes, El Caballero de la Esperanza. Na ocasião já carregava a alcunha de "escritor comuna" e precisou se exilar em Buenos Aires para produzir a obra; em 1939 ouviam-se os discursos de Getúlio Vargas em apoio ao Eixo e a perseguição aos militantes do Partido Comunista era contínua e violenta. Em 1941 e 1942, Amado sai do país e divide sua morada entre a Argentina e o Uruguai. Pouco se difundiu a respeito da producão intelectual e do engajamento político desneste artigo. Mais precisamente, parto da operação de "escova a história a contrapelo" (BENJAMIN, 2016) para problematizar o corrente discurso biográfico sobre Amado e sugerir um outro rearranjo narrativo com base em um acervo literário, desconhecido até 2012. A proposta se inscreve nos atuais postulados da crítica biográfica, que reconhecem a potencialidade literária desse gênero na intersecção entre fato e ficção, a considerar que "[...] a vida do escritor reverte-se necessariamente em grafia, e a biografia se traduz em literatura" (SOUZA, 2011).

PALAVRAS-CHAVE: Biografia; Acervo Literário; Jorge Amado; Walter Benjamin; 1941-1942.
* marinasiqueiradrey@gmail.com

Mestra em Literatura (2017) pela Universidade Federal de Santa Catarina (UFSC), Bacharela (2015) e Licenciada (2014) em LetrasLíngua Portuguesa pela mesma instituição. Atualmente é Doutoranda no Programa de Pós-Graduação em Literatura da UFSC; integra o Núcleo Literatura e Memória (NULIME/UFSC). http://lattes.cnpq
br/4059593420745384 https://orcid.org/0000-0002-6894-5567

ABSTRACT: In 1940s Jorge Amado published the biography Vida de Luiz Carlos Prestes, El Caballero de la Esperanza. At the time he was already carrying the nickname "commune writer" and had to go into exile in Buenos Aires to produce the work; in 1939 Getúlio Vargas' speeches in support of the Axis were heard and the persecution of Communist Party militants was continuous and violent. In 1941 and 1942, Amado leaves the country and divides his address between Argentina and Uruguay. Little has been said about the intellectual production and political engagement of those vears in the author's life and it is about this period that I dwell on this article. More precisely, I start from the operation of "brushing history against the grain" (BENJAMIN, 2016) to problematize the current biographical discourse about Amado and suggest another narrative rearrangement based on a literary collection, unknown until 2012. The proposal is part of the current ones postulates of biographical criticism, which recognize the literary potential of this genre at the intersection of fact and fiction, to consider that "[...] the life of the writer is necessarily reverted to spelling, and the biography is translated into literature" (SOUZA, 2011).

KEYWORDS: Biography; Literary Collection; Jorge Amado; Walter Benjamin; 1941-1942. 


\section{A HISTÓRIA E SEUS ECOS}

Na contemporaneidade, Walter Benja min (1892-1940) é tido como um dos pensadores mais célebres do século XX. Assim, é recorrente a descrição de sua produção como "original”, "inclassificável”, "a nticonvencional” etc. Tal singularidade, que desloca a possibilidade de interpretar o pensamento do autor em uma perspectiva meramente maniqueísta, apoia-se, segundo Löwy (2005), em três fontes basilares distintas e, em um primeiro plano, contraditórias: i) a influência do romantismo alemão, ii) o messianismo judaico, e iii) o marxismo. Em linhas gerais, segundo esse estudioso da obra de Benjamin, da primeira fonte vem a crítica à civilização moderna, da segunda, os conceitos teológicos centrais da obra, e, por fim, da terceira, o materialismo histórico.

Dessa forma, o norte que se precisa seguir para a compreensão dos postulados desse intelectual, portanto, é aquele no qual as três fundamentais estruturas mencionadas acima não podem ser tomadas como uma síntese que resolva Benjamin, pois aquilo que se deve projetar desse amálgama é, justa mente, sua não classificação. Mas o que, afinal, isso significa? Em um primeiro momento, a compreensão de que, desde o início, o pensa mento desse teórico não opera em uma perspectiva de um sistema filosófico e, além disso, em segundo lugar, que qualquer tentativa de identificar uma fratura epistemológica entre uma possível produção "idealista” na juventude e outra "materialista" no final da vida de Benjamin, não será capaz de alcançar a potencialidade filosófica, teórica e política de seus textos. (LÖWY, 2005).

Nesse contexto, as teses Sobre o conceito da História aparecem como exemplo típico da constituição desse pensamento, pois não apenas trazem para o seu interior elementos "materialistas" e "messiânicos" como ta mbém os tencionam, de modo que as referências messiânicas acabam por potencializar a discussão da crítica da/à História. É a partir dessa articulação que o teórico problematiza a lógica, o modus operandi e o produto do historicismo burguês: o progresso. Logo, não é de se estranhar que as teses redigidas em 1940 sejam consideradas um dos textos mais relevantes do século passado.

Assim, Benjamin se afasta das correntes do seu tempo ao afirmar que a evolução humana não seria alcançada por meio do progresso que, em verdade, e na direção oposta, só foi/é capaz de oferecer o abismo. "Abismo", aliás, que o próprio foi levado a se atirar quando, fugido do regime nazista, cometeu suicídio em 27 de setembro de 1940, ao não conseguir atravessar a fronteira da França com a Espanha. Não à toa, Löwy (2005, p. 87) 
1. "Apenas mostrar como realmente aconteceu". Tradução de Arno Wehling. utiliza a expressão "dimensão profética” para discorrer acerca dos, assustadoramente lúcidos, postulados de Sobre o conceito da História. Afinal, consta nesse texto a percepção de que o ápice da barbárie e do fascismo do século XX eram iminentes e, realmente: Auschwitz estava logo adiante e Hiroshima não tardou a chegar.

O que Benjamin faz chamar atenção, portanto, passa pela oposição à noção da história como um processo linear e contínuo de evolução, no qual aquele que se estabeleceu como vencedor deve ser tomado como símbolo absoluto de desenvolvimento, avanço. Em outras palavras, o autor problematiza a noção de história universal, fornecendo apa ratos para se fazer ver que "Articula historicamente o passado não significa reconhecê-lo 'tal como ele foi'. Significa apoderarmo-nos de uma recordação (Erinnerung) quando ela surge como um clarão num momento de perigo.” (BENJAMIN, 2016, p. 11). A indicação das aspas na passagem refere-se à declaração do historiador Leopold von Ranke (1979- 1886), que dizia ser tarefa do historiador descrever o passado como realmente foi: "[...] es will bloss zeigen wie es eigentlich gewesen ist ${ }^{1}$." (RENKE apud WEHLING, 1973, p. 1).

Fica claro, portanto, que Benjamin se opõe a tal concepção positivista, pois, para ele, o historiador não é capaz de descrever o passado "tal como ele foi", a considerar a impossibilidade da existência do sujeito neutro - aquele que se ocupa do que é real - já que a "História da Humanidade" foi sempre contada sob a ótica dos vencedores e, em vista disso, em verdade, é fruto do discurso do domina nte que, século após século, mantém-se como protagonista da/na historiografia. É nessa direção que as teses são escritas e, juntas, constituem um dos aportes teóricos mais contundentes para se pensar não somente o passado histórico, mas o próprio presente, haja vista que tal relação temporal passa a ser questionada em razão do campo de forças, ou de oposições, que a constitui.

Ademais, é pertinente a observação de que esse texto não foi elaborado com vistas à publicação ou, ao menos, não no forma to em que chegou ao público: 18 teses e dois apêndices, cuja relevância para o pensamento revolucionário é posta em compa ração, por alguns estudiosos da obra de Benjamin, com as Teses sobre Feuerbach, de Karl Marx. Além disso, é comum encontrarmos menções de aproximação do Sobre o conceito da História ao Passagens tanto pelo forma to fragmentário de a mbos quanto pelos pontos de intersecção em suas discussões.

A primeira publicação das teses ocorreu na Revista de Investigação Social e foi uma homenagem póstuma feita por 
Adorno e Horkheimer, em 1942. Para a edição, foi mandada uma nota em que Adorno comenta a troca de correspondências com Benjamin quando na elaboração do texto:

Este projeto de uma filosofia da História é o último dos trabalhos que Benja min deixou esboçado, e que não se destinava à publicação. "A guerra e a constelação que a gerou", diz-se na carta que acompanhava o original, "levou-me a pôr no papel algumas ideias das qua is posso dizer que andava $\mathrm{m}$ comigo, ou melhor, de mim próprio escondidas, há perto de vinte anos. [...] Não sei até que ponto a leitura te irá surpreender ou, coisa que não desejo, confundir. De qualquer modo, queria chamar a tua atenção especialmente para a reflexão XVII, porque é a1 que se poderão reconhecer as ligações, escondidas mas esclarecedoras, destas considerações com os trabalhos que tenho escrito até aqui, na medida em que nela se expõe de forma concentrada o método desses trabalhos. (ADORNO apud BARRENTO, 2016, p. 169).

A Tese XVII, destacada por Benjamim na correspondência, discorre sobre o que foi denominado genericamente por ele de "historicismo", isto é, a versão uníssona da história cujo processo de dominação social é inerente:

O Historicismo culmina, como tinha de ser, na história universal. [...] O seu método é aditivo: oferece a massa dos fatos acumulados para preencher o tempo vazio e homogêneo. A historiografia materialista, por seu lado, assenta sobre um princípio construtivo. Do pensar faz parte não apenas o movimento dos pensamentos, mas ta mbém a sua paragem. Quando o pensar se suspende subitamente, numa constelação carregada de tensões, provoca nela um choque através do qual ela cristaliza e se transforma numa mônada. O materialista histórico ocupa-se de um objeto histórico apenas quando este se lhe apresenta como tal mônada. Nessa estrutura, ele reconhece o sinal de uma paragem messiânica do acontecer ou, por outras palavras, o sinal de uma oportunidade revolucionária na luta pelo passado reprimido. E aproveita essa oportunidade para forçar uma determinada época a sair do fluxo homogêneo da história [...]. (BENJAMIN, 2016, p. 19).

A proposição contrária à concepção do método aditivo da histografia, que acumula o tempo histórico sob uma perspectiva linear e contínua, é melhor compreendida ao recorrermos à Tese VII, na qual consta a frase mais famosa de Benjamin no tocante à prática historiográfica crítica: aquela em que postula a necessidade de se "escovar a história à contrapelo" (BENJAMIN apud LÖWY, 2005 , p. 70, Tese) como alternativa para firmar a recusa em se juntar ao discurso homogêneo dos vencedores; pois, segundo o autor, "Todo aquele que, a té hoje, obteve a vitória, marcha junto no cortejo de triunfo que conduz 
os dominantes de hoje [a marcharem] por cima dos que jazem por terra." (BENJAMIN apud LÖWY, 2005, p. 70)." É por esse motivo que cabe ao materialista histórico, na tarefa de escovar a história a contrapelo, subverter as narrativas contemplativas do passado a partir de seu lugar no tempo presente, que passa a ser, por conseguinte, um lugar da crítica.

É, enfim, com o intuito de propor uma operação crítica em relação ao passado, valendo-me das reflexões suscitadas pelo Sobre o conceito da História, que problematizo o discurso biográfico de um dos mais populares escritores da literatura brasileira: Jorge Amado. Mais especificamente, refiro-me ao registro histórico de dois anos de sua vida, 1941 e 1942, período o qual suas narrativas biográficas mais canônicas, grosso modo, indicam como aquele em que publicou $A B C$ de Castro Alves e partiu para o Uruguai (1941) e Buenos Aires (1942) a fim de escrever uma biografia laudatória a Luiz Carlos Prestes, dado o envolvimento do escritor como militante do Partido Comunista Brasileiro - PCB (Partido Comunista do Brasil na época).

Como se pode notar pela indicação das datas, o intervalo biográfico em questão corresponde ao momento histórico que vitimou Walter Benjamin no início dos 1940; mas, mais do que isso, constitui-se também como resultado de tais acontecimentos. Isso porque a ruptura do sistema liberal-democrático que se deu no Brasil a partir de 1937, com o Estado Novo, foi uma repercussão do que ocorria em países centrais do mundo, como a Itália com Mussolini, a ex-URSS com Stálin, e a Alemanha com Hitler. No caso do Brasil, é válido lembrar que, dois meses antes da promulgação do regime estadonovista de Getúlio Vargas, a "a meaça comunista" do Plano Cohen ${ }^{2}$ era anunciada pelo general Góis Monteiro ${ }^{3}$ em uma comunicação de rádio no Hora do Brasil, em rede nacional.

Assim, nessa conjuntura, o a núncio da Segunda Guerra Mundial, em 1939, só fez aumentar a perseguição aos militantes comunistas no país, atestada explicitamente já em 1936, quando Vargas deportou Olga Benário para a Alemanha nazista, sob a justificativa de que a militante era uma ameaça à segurança do país. Nesse momento histórico, Jorge Amado já era um nome visado: ta mbém em 1936 foi preso, acusado de participar da Intentona Comunista (1935), e o mesmo ocorreu em 1937, devido à supressão de liberdade política instaurada pelo Estado Novo. Ainda em 1937, teve 1640 exemplares de livros, entre Capitães da Areia, Mar Morto, Cacau, Suor, Jubiabá e o País do Carnaval, queimados em praça pública. "Incinerados vários livros considerados propagandistas
2. Na notícia, Monteiro relata o Plano como um documento apreendido uma estratégia de tomada do país pelo Partido Comunista Brasileiro (PCB). Frente à autenticidade do (PCB). Frente à autenticidade do
documento e à "ameaça vermelha" documento e à "ameaça vern quando o líder comunista Luiz Carlos Prestes declarou apoio à Aliança Nacional Libertadora (ANL) e, por conseguinte, à Intentona Comunista, pois é de responsabilidade da ANL, organização de cunho político antifascista e anti-imperialista, os movimentos armados de 1935 - Vargas solicitou ao Congresso Nacional a decretação do Estado de Guerra e, assim, fez uso dos poderes legais dessa condição iniciando uma ferrenha perseguição aos comunistas, bem como a qualquer opositor político e, no dia $1^{\circ}$ de novembro, instaurou a ditadura do Estado assumido como uma frauda justificar a instauração do golpe de

3. Chefe do Estado Maior do Exército Brasileiro. 
4. União Soviética, Reino Unido e Estados Unidos. do credo vermelho", dizia a manchete do Jornal do Estado da Bahia, de 17 de dezembro daquele ano.

É, portanto, nesse contexto político, nacional e mundial, que o escritor autoexilou-se, em 1941-1942, nos vizinhos latinoamerica nos para redigir a biografia de Luiz Carlos Prestes, cuja publicação ocorreu em 1942 sob o título de Vida de Luís Carlos Prestes, el Caballero de la Esperanza. Ainda nesse mesmo ano, em virtude da manifestação do governo brasileiro em apoio aos Aliados ${ }^{4}$ ele regressou ao Brasil na crença de que "tudo o mais se torna secundário" (AMADO, 2006, p. 297) diante da necessidade de se derrotar Hitler. Na ocasião, tanto Amado quanto importantes figuras da cúpula do partido dispuseram-se a retornar ao país para, "em torno de Getúlio" (AMADO, 2006, p. 297), combaterem a onda fascista mundial da década. Não precisou, no entanto, de uma semana em solo brasileiro para o "escritor comuna" ser localizado e, posteriormente, preso no Rio de Janeiro.

As informações mencionadas no parágrafo acima compilam as menções mais recorrentes nas narrativas biográficas de Jorge Amado sobre os acontecimentos de 1941 e 1942. Nessas leituras, pouco se sobressalta o leitor em relação ao período de expatriação em questão, uma vez que é discurso comum nessas obras, unanimemente, identificar o segundo afastamento político de Amado (1948-1952) como "o" exílio de sua vida. Ilustro:

Em sua casa, no Quai des Célestins, em seu exílio voluntário, Jorge Amado me apresentou Alice Raillard, com quem passei, dias depois, uma agradável tarde de julho, às vésperas do bicentenário da Revolução Francesa, onde pudemos conversar sobre Jorge, Glauber, Vinícius, Darcy Ribeiro, entre tantos que fizeram história literária em nosso país. (NERY, 1990, p. 12 , grifos meus). ${ }^{5}$

1941 - Conclui $A B C$ de Castro Alves, entrega os originais à Livraria Martins Editora que passa a ser a editora exclusiva de seus livros. (mar.)

Decide escrever um livro sobre Luís Carlos Prestes, pensando numa campanha pela anistia. Sai do Brasil em busca de material para o livro. Vive entre 1941 e 1942 na Argentina e no Uruguai, pesquisando. [...]

1948 - Seu mandato de deputado é cassado pela Câmara Federal por ter sido cancelado o registro do Partido Comunista, do qual ele fazia parte (8 de jan.)

Nesta época, possuir livros de Jorge Amado era altamente comprometedor. Quando encontrados pela polícia eram apreendidos como material subversivo.
5. Nery não localiza data, além de marcar o adjunto no singular, o que pode sugerir, àqueles que pouco conhecem a biografia do escritor baiano, que houve apenas vida de Amado sendo a passagem recém descrit sendo a passagem recêt descrita se fala do episódio $48-52$. 
6. O rompimento oficial de Jorge Amado com o PCB se deu somente em 1955.
Viaja para Europa em exilio voluntário. (RUBIM; CARNEIRO, 1992, p. 38-44, grifos meus).

Nesse contexto, o período de 1941-1942, em vista disso, passa a ser identificado como menor nas escritas biográficas que o toma m como protagonista, no sentido de ser diminuída tanto a urgência política de perseguição na conjuntura do Estado Novo quanto a própria relação do escritor com o que denominou de "alta direção do Partido” (AMADO 1990 apud RAILLARD, 1990, p. 104), pois, ao escrever Vida de Luís Carlos Prestes, el Caballero de la Esperanza, foi servir à ca mpanha em sua a nistia. Além disso, soma-se o fato de que o próprio Jorge Amado a firmou que nunca socializou, e sequer viria a socializar, os acontecimentos referentes ao intervalo de tempo em que manteve relação direta com o Partido6: "Sobre tais lembranças não fiz a notações, morrem comigo" (AMADO, 2006, p.14), decla rou. Desse modo, passaram-se décadas para que esse recorte biográfico do passado fosse despertado no presente; e é sobre esse la mpejo que discorro a seguir.

\section{0 "LAMPEJO BIOGRÁFICO":}

\section{O OLHAR PARA O PASSADO}

1942, Porto Alegre: Jorge Amado desembarca à procura de Cordeiro de Farias, na ocasião interventor do
Estado no Rio Grande do Sul ${ }^{7}$, em missão determinada por Rodolfo Ghioldi, dirigente do PC Argentino: o escritor baia no deveria recorrer à influência de Farias para romper o isolamento de Luiz Carlos Prestes em Ilha Grande. Embora em início de carreira, com recém completos 30 a nos, Amado já contava com reconhecimento nacional dada a publicação de seis romances, um livro de poemas e duas biografias ${ }^{8}$, sendo a última a obra laudatória a Prestes aqui já mencionada.

No episódio, Ghioldi apostou tanto no prestígio do escritor quanto no ego de Farias, um dos comandantes da Coluna Prestes que recebeu menção elogiosa na biografia em questão, sendo descrito por Jorge Amado como um dos heroicos membros da marcha de 1925-1927. Vida de Luiz Carlos Prestes, el caballero de la Esperanza, publicada pela Editora Claridad ${ }^{9}$, como dito, fez parte da campanha do partido em prol da anistia de Prestes, preso em 1936 quando encontrado pelo DOPS (Departamento de Ordem Política e Social' em uma pequena casa no Méier, zona norte do Rio de Janeiro.

Farias efetivamente recebeu o escritor e militante do partidão, ouviu o recado, reiterou sua simpa tia pelo líder da Coluna (mesmo após ter rompido com o PC), mas, embora tenha se comprometido a tentar, não podia garantir
7. Governador nomeado pelo Presidente da República. Na ocasiáo do

8. Romances: O País do Carnaval (1931), Cacau, (1933), Suor (1934), Jubiabá (1935), Mar morto (1936) Capitães da areia (1937). Poesia: A estrada do mar, em coautoria com Matilde Garcia Rosa (1938). Biografias: $A B C$ de Castro Alves

9. No Brasil, a biografia foi publicada somente em 1945, com o título de o Cavaleiro da Esperança. 
10. Eurico Dutra foi ministro da Guerra. Junto com o general Góis Monteiro, apoiou Getúlio Vargas n instauração da ditadura do Estado Novo, em novembro de 1937 . Filinto Müller foi o responsáve por enviar Olga Benário para um campo de concentração nazista na Alemanha, onde foi executada em 1942. o feito, o problema era Dutra, Filinto e Góes Monteiro ${ }^{10}$. Na despedida, diz ao escritor (2006, p. 298): "Vá ficando por aqui, mas se receber ordens do Rio não terei outro jeito senão mandar lhe prender [...]”. De fato, dias depois, Jorge Amado partiu da capital gaúcha em um trem, escoltado por um policial, rumo ao Rio de Janeiro, onde ficou preso na Casa de Correção. Todavia, o escritor foi pego sem nenhum material que o comprometesse e, cerca de três meses depois, acabou sendo posto em liberdade, sob a condição de fixar residência obriga tória em Salvador e se apresentar semanalmente à Delegacia de Ordem Política e Social.

Essa história teria sido outra se Jorge Amado tivesse embarcado para Porto Alegre, nas vésperas da missão com Farias, com aquilo que recolheu e produziu enquanto esteve exilado em Montevidéu e Buenos Aires: reportagens, fotografias, contratos editoriais, textos literários em prosa e em versos - estes não apenas em relação a Luís Carlos Prestes - correspondências trocadas com militantes do PC e da ANL etc. Tudo isso, cerca de 1.500 páginas de documentos, foi deixado para trás pelo escritor, e 70 a nos depois veio à tona, já que uma militante comunista os guardou na ocasião de partida de Jorge Amado, em 1942. Rosa, nome que escolheu para ser identificada - uma homenagem à Rosa de Luxemburgo ficou com esses papeis até o fim da vida, de forma que sua herdeira, Leonor, tornou-se a responsável pela doação, e consequente socialização, dos documentos.

Atualmente, eles constituem o corpus do Acervo Mala de Jorge Amado ${ }^{11}$, denominação que alude à condição em que foram reunidos no exílio: em uma mala. Assim para o estudo desse material, distintos recortes, de distintas pesquisas, têm sido feitos, mas, foi somente em 2015, na ocasião de pesquisa acadêmica, que o "la mpejo" (BENJAMIN, 2005) dessa imagem biográfica foi visto. Recorro à metáfora, nesse caso, como referência à Tese V, de Sobre o conceito da História, na qual se lê:

A verdadeira imagem do passado passa célere e furtiva. $\mathrm{E}$ somente como imagem que lampeja justamente no instante de sua recognoscibilidade, para nunca mais ser vista, que o passado tem de ser capturado. "A verdade não nos escapará” - essa frase de Gottfried Keller indica, na imagem que o Historicismo faz da história, exatamente o ponto em que ela é batida em brecha pelo materialismo histórico. Pois é uma imagem irrestituível do passado que ameaça desaparecer com cada presente que não se reconhece como nela visado. (BENJAMIN apud LÖWY, 2005, p. 62).

Quer dizer, "verdadeira imagem do passado" porque incide sobre o presente de forma a operar como um
11. Desde 2011, o acervo está no Núcleo Literatura e Memória (Nulime) da UFSC, tornandose objeto de estudo a partir de 2012, quando pesquisadoras de 2012, quando pesquisadoras de e Doutorandas passaram a pesquisá-lo. 
procedimento crítico e, por isso, nunca recuperável porque não estática. Dessa forma, Benjamin afirma, mais uma vez, a impossibilidade da apreensão da verdade pretendida pelo historicismo. Segundo Löwy (2005), podemos compreender melhor as implicações políticas dessas relações motivadas por essa(s) imagem(s) se retomarmos algumas variantes das teses, pois, conforme aponta, essa conexão com o passado

[...] é explicitada em uma das nossas notas preparatórias da tese: "Esse conceito [do presente] cria entre a escrita da história e a política uma conexão, idêntica àquela, teológica, entre a rememoração e a redenção. Esse presente se traduz em imagens que podem ser chamadas de dialéticas. Elas representam uma intervenção salvadora (rettenden Einfall) da humanidade." (GS I, 3, p.1248). Reencontramos a ideia paradoxal - mas essencial à atitude intelectual de Benjamin - de uma espécie de identidade entre certos conceitos teológicos e seus equivalentes profanos, revolucionários. Por outro lado, não convém perder de vista que a "intervenção salvadora" tem por objeto tanto o passado quanto o presente: história e política, rememoração e redenção são inseparáveis. (LÖWY, 2005, p. 62).

Assim, sob essa perspectiva, o "la mpejo biográfico" desse Acervo apresenta-se como uma outra forma para se contar a história desses dois anos da década de 40 , pois rompe com a tradição do discurso do vencedor, a considerar a pluralidade de "peças" que o constituem e que foram desconsideradas tanto no discurso dominante da história de vida de Jorge Amado e, por conseguinte, da própria história da literatura brasileira. Isto é, consta na "montagem” das peças desse arquivo a operação do pensar a história a contrapelo como oposição à ideia de uma projeção linear do tempo, como o faz o historicismo, a considerar que um acervo literário, por excelência, é descontínuo e livre de qualquer pretensão de fechamento, pois

[...] os arquivos estão sempre inacabados, na medida em que podem acolher novos documentos e materiais. Pode-se dizer que são um verdadeiro Work in progress. [...] cada arquivo, em cada tempo e lugar, privado ou institucional, comporta uma história e uma configuração particulares, irredutíveis a uma história totalizante. (MARQUES, 2001, p. 201)

Nesse sentido, o Acervo comporta muitas histórias nas cerca de 1500 páginas que o constituem, a exemplo daquelas relativas aos 38 remetentes que escreveram para Jorge Amado entre 1941 e 1942, dentre os quais editores, como José de Barros Martins (Editora Martins) e Antonio Zamora (Editorial Claridad), a migos pessoais e de militância, como Ivan Pedro de Martins e Pedro Mota 
12. “[...] eu me aventurei pouco em outros gêneros. Eu sou mesmo um romancista" (AMADO 1997 apud CADERNOS DE LITERATURA
BRASILEIRA 1997, p. 44).
Lima, intelectua is la tinoa merica nas, como Alba Roballo e Carmen Alfaya Ghioldi, e muitos outros.

Além disso, o arquivo ainda é capaz de descrever e contextualizar grande parte da produção intelectual do escritor no período, oferecendo, portanto, um discurso distinto daquele que, majoritaria mente, se convencionou reproduzir nas suas narrativas biográficas mais canônicas - que, como já dito, resumem-se a citar $A B C$ de Castro Alves (1941) e Vida de Luís Carlos Prestes, el Caballero de la Esperanza (1942) -, a começar pelos originais de artigos publicados em periódicos, como o Toda uma literatura suicidou-se com Stefan Zweig, texto cuja publicação ocorreu no jornal La Razón de 25 de fevereiro de 1942, passando pelas cópias das conferências que proferiu, como o Leocádia, Olga e Anita, comunicação sobre a mãe, a esposa e a filha de Luís Carlos Prestes para o Liceo Rosarino de Mulheres (Rosario/Argentina, 12 de novembro de 1941), até chegar nos datiloscritos de sua criação literária, que englobou diversos gêneros como o poema, o conto, o roteiro e o romance.

A respeito dessa produção de literatura, destaco a recorrência de poemas, uma vez que Jorge Amado publicou raros textos dessa natureza ao longo de sua trajetória como escritor, "Eu sou mesmo um romancista"12, repetiu o longo da vida. Além disso, não menos importantes são os originais de dois romances no a rquivo, o São Jorge dos Ilhéus/Agonia da Noite e o São Jorge dos Ilhéus/Terras do Sem Fim. O primeiro, diz respeito a um romance inacabado e a té hoje inédito, cujas cópias são intituladas ora São Jorge dos Ilhéus, ora Agonia da Noite; o enredo, de caráter intimista, apresenta um grupo de comunistas em volta de um aparelho de rádio às vésperas de um levante. O segundo, traz as partes iniciais da obra posteriormente publicada como Terras do Sem Fim (1943), mas inicialmente denominada nos originais de São Jorge dos Ilhéus.

Em vista das considerações compartilhadas, portanto, é possível afirmar que, embora as obras de caráter biográfico justifiquem a sua publicação assegurando o compartilhamento de dados a respeito da vida e da obra do autor, nenhuma delas, de fato, consegue superar a tessitura biográfica de Amado para além do discurso canônico estabelecido quando se referem aos a nos de 1941 e 1942. Desse modo, a proposta de escrever uma biografia, a partir do Acervo Mala de Jorge Amado, intenciona a reivindicação da ta refa que Walter Benja min atribuiu ao materialista histórico, o "escovar a história a contrapelo" como forma de subversão às narrativas contemplativas do passado a partir do tempo presente. É sobre essa operação que discorrerei a seguir. 
3 SOBRE O “LAMPEJO BIOGRÁFICO": O OLHAR PARA

\section{O PRESENTE}

Para continuar a discussão da operação de descontinuidade da história, por meio da conexão do presente com o passado "lido" no momento do agora, tomo como norte a valiosa sugestão de Löwy (2015) nas reflexões de leitura da Tese $\mathrm{V}$, mencionadas anteriormente neste ensaio. Isto é, retorno à "imagem dialética", conceito desenvolvido por Benja min no fragmentário e intenso texto das Passagens (2006).

$\mathrm{Na}$ obra, a noção de imagem dialética coloca a problemática da materialização do passado sendo, ao mesmo tempo, condição e instrumento operatórios para a legibilidade da história. Isto é, a partir da percepção de uma nova época, a da reprodutibilidade e da técnica, Benjamin aponta a fulguração como qualidade instrínseca a essa imagem que se torna "dialética na imobilidade", já que, enquanto o passado e o presente relacionam-se sob uma perspectiva temporal e contínua, a correspondência do acontecido e da a tualidade torna-se dialética, pois "salta" em vez de progredir:

O índice histórico das imagens diz, pois, não apenas que elas pertencem a uma determinada época, mas, sobretudo, que elas só se tornam legíveis numa determinada época. E atingir essa legibilidade constitui um determinado ponto crítico específico do movimento em seu interior. Todo o presente é determinado por aquelas imagens que lhe são sincrônicas: cada agora é o agora de uma determinada cognoscibilidade. Nele, a verdade está carregada de tempo até o ponto de explodir (Essa explosão, e nada mais, é a morte da intentio, que coincide com o nascimento do tempo histórico autêntico, o tempo da verdade). Não é que o passado lança sua luz sobre o presente ou que o presente lança luz sobre o passado; mas a imagem é aquilo em que o ocorrido encontra o agora num lampejo, formando uma constelação. Em outras palavras: a imagem é a dialética na imobilidade. Pois, enqua nto a relação do presente com o passado é puramente temporal, a do ocorrido com o agora é dialética - não de natureza temporal, mas imagética. Somente as imagens dialéticas são autentica mente históricas, isto é, imagens não arcaicas. A imagem lida, quer dizer, a imagem no agora da cognoscibilidade, carrega no mais alto grau a marca do momento crítico, perigoso, subjacente a toda leitura (BENJAMIN, 2006, p. 504- 505 [N 3, 1]).

Dessa forma, ela representa um recorte do passado que é retirado do fluxo histórico e adquire sua legibilidade no presente. Logo, não se trata, pois, de uma determinação temporal contínua entre o passado e o presente, mas de uma relação que "pulou" para o agora a fim de uma tradução própria desse tempo. 
Em outras palavras, cada tempo, cada presente, lê seu próprio passado reunindo as urgências do que foi e do que é. E que outro passado ou outras urgências teriam o tempo do agora senão aquelas descritas por Benja min em Sobre o conceito da História? Mais especifica mente, pensando no contexto do cenário político brasileiro atual, vimos se repetir, de modo análogo, resguardadas especificidades de cada época, o próprio entorno dos anos de 1940 que, agora, "no instante de sua recognoscibilidade" (BENJAMIN, 2005), motivam a prática da crítica para o ontem e para o hoje, de modo que, como já escreveu Benja min (2016, p. 13, Tese VIII]): "'o estado de exceção' em que vivemos é a regra". Nessa conjuntura, a imagem dialética aparece como uma imagem do desejo do artista insatisfeito com o presente. Para elucidar essa questão, Benja min retoma a seguinte passagem de Jung:

[...] o desejo se retrai até atingir no inconsciente a imagem arquetípica, apta a compensar a unilateralidade do espírito do tempo. O desejo apodera-se desta imagem e, ao aproximá-la da consciência, muda também sua forma até que ela possa ser apreendida pelo homem do presente segundo sua capacidade de compreensão. (JUNG, 1932 apud BENJAMIN, 2006, p. 514).

É nesse contexto que se atenta para as rupturas das visões tradicionais da história, dado que os arquétipos podem sem interpretados a partir dos desejos do tempo presente. Assim, essa imagem tanto destrói o fio da continuidade quanto reivindica um tempo que há por vir. Em certa medida, é uma condensação do tempo a partir de colagens de impressões que rememoram determinada historicidade revisitada pelo agora. Nessa direção, ler o Acervo Mala de Jorge Amado como tessitura biográfica é um exercício da prática a contrapelo, na medida em que a "acumulação" descontínua dos acervos dá legibilidade para a temporalidade atravessar a sua elaboração do passado ao presente, pois um acervo é um espaço aberto. Dessa forma, segundo Leonor Arfuch (2009, p. 372-373),

O arquivo e a biogra fia são construídos a partir desse eixo indissociável [espaço e temporalidade], já que a simples lembrança ou vivência - como o texto, a fotografia, o objeto - trazem consigo o tempo e o lugar. Contudo, essa dimensão da experiência, que para Ricoeur articula toda e qualquer narrativa, se encontra distante da linha canônica de um devir datado, atestado de uma concatenação harmônica de acontecimentos. Pelo contrário, o "ordenamento" do arquivo, expressão já presente desde o distante vocábulo grego - que é, como a narrativa, uma disposição de forma e de sentido - depende exclusiva mente da trama, desse tecido caprichoso que tanto a memória como a escrita, ou a busca de indícios que aproxima $\mathrm{o}$ a rquivista do detetive, possa $\mathrm{m}$ requerer. $\mathrm{O}$ rela to não repõe 
uma ordem prévia da vida, a qual concebe como inexistente, já que se trata de uma ordem construída performaticamente, no próprio trabalho da narração, o que comprova o trabalho narrativo do arquivo. Recorrendo a Derrida, "o arquiva mento, além de registrar, produz o acontecimento".

Por fim, é nessa direção de revisão e reconstrução que esse "la mpejo biográfico" se propõe, a considerar que a leitura dos registros desse a rquivo são postas como uma abertura de discussão sobre o passado no presente e, por isso, um exercício de descontinuar os discursos da história dos vencedores.

\section{REFERÊNCIAS}

AMADO, JORGE. Navegação de Cabotagem: apontamentos para um livro de memórias que jamais escreverei. Rio de Janeiro: Editora Record, 2006.

ARFUCH, Leonor. A auto/biografia como (mal) de arquivo Trad. Rômulo Monte Alto e Mayla Santos Pereira. In: SOUZA Eneida Maria de; MARQUES, Reinaldo (Org.). Modernidades alternativas na América Latina. Belo Horizonte: UFMG: 2009. p. 370-382.

BARRENTO, João (org.) O Anjo da História. Belo Horizonte: Autêntica Editora, 2016.
BENJAMIN, Walter. Passagens. Belo Horizonte: Editora UFMG; São Paulo: Imprensa Oficial do Estado de São Paulo, 2006.

Sobre o conceito da História. In: BARRENTO, João (org.) O Anjo da História. Belo Horizonte: Autêntica Editora, 2016. P. 07-20.

CADERNOS DE LITERATURA BRASILEIRA: Jorge Amado. São Paulo: Instituto Moreira Salles, n. 3, 1997.

CUNHA, Eneida Leal. A Casa Jorge Amado. IN: SOUZA, Eneida Maria de; MIRANDA, Wander Mello (Org.). Arquivos Literários. São Paulo: Ateliê Editorial, 2003. p.117-128.

\section{RANCO, Renato. 10 Lições sobre Walter Benjamin.}

Petrópolis/RJ: Editora Vozes, 2015

LÖWY, Michael. Walter Benjamin: aviso de incêndio. São Paulo: Boitempo Editorial. 2005

MAROUES, REINALDO. O que nos resta nos arquivos literários. In. MIRANDA, Wander Melo; SOUZA, Eneida Maria de (Orgs.). Crítica e Coleção. Belo Horizonte: Editora UFMG 2011. p. 192- 203. 
NERY, Hermes Rodrigues. A dinâmica criadora de Jorge

Amado, 1990. In. RAILLARD. Alice. Conversando com Jorge

Amado. Trad. Annie Dymetman. Rio de Janeiro, Record.

1990

RUBIM, Rosane. CARNEIRO, Maried (orgs.). Jorge Amado

80 anos de vida e obra: subsídios para pesquisa. Salvador:

Casa das Palavras, 1992

SOUZA, Eneida Maria de. Janelas Indiscretas - Ensaios de

crítica biográfica. Belo Horizonte: Editora UFMG, 2011.

WEHLING, Arno. Em torno de Ranke: a questão da

objetividade histórica. Revista de História, São Paulo, p.1-

24, 1973. Disponível em: <http://www.revistas.usp.br/

revhistoria/article/view/131940>. Acesso em: 30 jan. 2019

Enviado em: 05/03/2020

Aceito em: 30/10/2020 